\title{
Mast cells degranulation affects angiogenesis in the rat uterine cervix during pregnancy
}

\author{
J Varayoud*, J G Ramos*, V L Bosquiazzo, M Muñoz-de-Toro and E H Luque \\ Laboratorio de Endocrinología y Tumores Hormonodependientes, School of Biochemistry and Biological Sciences, \\ Universidad Nacional del Litoral, Casilla de Correo 242, (3000) Santa Fe, Argentina
}

Correspondence should be addressed to E H Luque; Email: eluque@fbcb.unl.edu.ar

*J Varayoud and J G Ramos contributed equally to this work

\begin{abstract}
During pregnancy, it is essential that sufficient nutrients are supplied by the vascular system to support the dramatic modifications of the rat uterine cervix. Angiogenesis refers to the growth of new blood vessels from pre-existing microcirculation and mast cells have been associated with this process. This study examined the modifications of the vascular compartment and the distribution of mast cells on cervical tissue during pregnancy. Using disodium cromoglycate as a mast cell stabilizer, we determined the effects of the mast cell degranulation on cervical angiogenesis. Mast cell distribution and their degranulation status were evaluated by immunohistochemistry. Endothelial cell proliferation was measured by bromodeoxyuridine incorporation. Vascular areas (absolute and relative) and maturation indices were assessed by quantitative immunohistochemistry of von Willebrand factor and $\alpha$-smooth muscle actin respectively. Mast cells were predominantly observed during the first half of pregnancy in the perivascular zones. The values of bromodeoxyuridine incorporation, absolute vascular area and vascular maturation index exhibited a significant increase throughout pregnancy. All animals that received mast cell stabilizer showed more than $40 \%$ of non-degranulated mast cells. Treated rats exhibited a decrease in endothelial proliferation and in relative vascular area; in addition, a large proportion of mature blood vessels was observed, suggesting a diminished level of new vessel formation. The effects of the mast cell stabilizer were sustained beyond the end of treatment. This is the first report that brings evidence that mast cell degranulation could be a necessary process to contribute to the normal angiogenesis of the rat cervix during pregnancy. Further investigations are needed to elucidate the possible implications of abnormal vascular development of the uterine cervix on the physiological process of ripening and parturition.
\end{abstract}

Reproduction (2004) 127 379-387

\section{Introduction}

In order to retain the foetus inside the uterus, the uterine cervix must resist tension and remains rigid throughout most of the gestation. At term, however, the cervix softens and dilates through a process known as cervical ripening (Shi et al. 2000). The physiological mechanism of this process is extremely complex and involves molecular interactions between epithelial and stromal cells and the extracellular matrix composed mainly of collagen, elastin and glycosaminoglycans (Junqueira et al. 1980, Stygar et al. 2002). At parturition, fibroblasts and immune cells that reside and migrate within the pregnant cervix have been associated with the enzymatic remodelling of the fibrous connective tissue. During labour, widespread collagenolysis and changes in proteoglycan metabolism are synchronized with leukocyte infiltration and an increase in vascular permeability (Luque et al. 1996,
Thomson et al. 1999, Maymon et al. 2000). All of these cellular processes are energy demanding, and a vascular system providing sufficient nutrient supply is essential. Moreover, changes in vascular permeability and leukocyte infiltration observed at term strongly suggest an active role of the cervical vascular compartment during parturition (Hyder \& Stancel 2000).

Angiogenesis refers to the growth of new blood vessels from pre-existing microcirculation and requires endothelial migration, proliferation and stabilization (Levi Schaffer \& Pe'er 2001). Although it is substantially an endothelial cell event, there are other cells types and many kinds of mediators involved in this process (Griffioen \& Molema 2000, Hiromatsu \& Toda 2003). For almost 20 years, in vitro and in vivo studies have linked mast cell (MC) degranulation and activation with angiogenesis and neovascularization (Folkman 1982, Levi 
Schaffer \& Pe'er 2001, Norrby 2002). This assumption is partially supported by the close anatomical association between MCs and the vasculature, and the recruitment of these cells during tumour growth, wound healing and inflammation (Benítez-Bribiesca et al. 2001, Fukushima et al. 2001, Norrby 2002). Moreover, degranulation of MCs by a variety of secretagogues causes the release of potent angiogenic factors, e.g. vascular endothelial growth factor (VEGF), basic fibroblast growth factor (bFGF) and several interleukins (IL) such as IL-1 and IL-6 (Burd et al. 1989, Selvan et al. 1994). Many authors have described clusters of MCs in the myometrium and endometrium of non-pregnant women, proposing active roles for these cells in the control of implantation and in extracellular matrix remodelling during the menstrual cycle (Mori et al. 1997, Vincent et al. 2000). Moreover, it has been suggested that MCs could regulate contractility of the myometrium during labour in women (Rudolph et al. 1993). A recent study showed that MCs and their mediators are capable of regulating cervical contractility in animals in mid-pregnancy, and possibly contribute to cervical competence during pregnancy in guinea pigs (Bytautiene et al. 2002). Despite the advances in pregnancy and parturition physiology, the role of MCs in the pregnant cervix remains unclear.

We have hypothesized that MCs promote new vessel formation in the pregnant rat uterine cervix by a degranulation process. The present study examined in detail the physiological modifications of the vascular compartment and the distribution of MCs in the cervical tissue during pregnancy. The aim of this work was to investigate the effects of the inhibition of MC degranulation on angiogenesis in the rat uterine cervix during pregnancy.

\section{Materials and Methods}

\section{Animals}

The study used female adult rats (weight, 200-250 g) of a Wistar-derived strain that was bred at the Department of Human Physiology (Santa Fe, Argentina). Animals were maintained in a controlled environment $\left(22 \pm 2{ }^{\circ} \mathrm{C}\right.$; lights on from 0600 to $2000 \mathrm{~h}$ ) and had free access to pellet laboratory chow (Cooperación, Buenos Aires, Argentina) and tap water. To obtain pregnant specimens, pro-oestrous females were caged overnight with males of proven fertility. Day 1 of pregnancy (D1) was defined as the presence of spermatozoa in the vaginal smear (Freeman 1994, Montes \& Luque 1988). In our colony, delivery occurred on D23. All rats were handled in accordance with the principles and procedures outlined in the Guide for the Care and Use of Laboratory Animals issued by the US National Academy of Sciences.

\section{Treatments and experimental groups}

Rats were randomly assigned to each of the different experimental groups (five or six animals per group). The first set of rats was injected i.p. with the thymidine analogue bromodeoxyuridine (BrdU, $60 \mathrm{mg} / \mathrm{kg}$ body weight, Sigma) $2 \mathrm{~h}$ before they were killed. In order to evaluate angiogenesis during pregnancy, whole cervices with adjacent portions of both horns and vagina were dissected on D9, D12, D14, D15, D18 and D22. Another set of pregnant rats was used to evaluate the effects of MC stabilizer treatment on cervical angiogenesis. Each experimental rat was allocated to one of three (a-c) experimental groups: (a) T14, treated with the MC stabilizer, disodium cromoglycate (i.p. $87 \mathrm{mg} / \mathrm{kg}$ body weight, Sigma), daily from D12 to D14 and killed on D14; (b) T18, treated with MC stabilizer from D12 to D18 and killed on D18; (c) T22, treated with MC stabilizer from D12 to D18 and killed on D22; or equivalent control groups injected i.p. with saline solution (C14, $\mathrm{C} 18$ and C22). The disodium cromoglycate dose was chosen using the criteria of 'minimal dose that has observed effects'; this is equivalent to the dose of another MC stabilizer (FPL 55618) used previously (Spanggaard et al. 1997). The experimental protocol for MC stabilizing treatment and the times when the rats were killed are shown schematically in Fig. 1.

Tissue samples were fixed by immersion in $10 \%$ buffered formalin for $6 \mathrm{~h}$ at $4{ }^{\circ} \mathrm{C}$, and embedded in paraffin. Serial sections ( $5 \mu \mathrm{m}$ thick) of whole cervices were taken along the cervical canal and mounted on 3-aminopropyl triethoxysilane (Sigma)-coated slides and dried for $24 \mathrm{~h}$ at $37^{\circ} \mathrm{C}$.

\section{Histotechniques}

MC evaluation was performed in consecutive sections stained either with $0.5 \%$ toluidine blue (Wolman, 1971) or immunostained for the detection of the rat mast cell proteinase-I (RMCP-I) (Gibson \& Miller 1986). Immunostaining was performed following the immunoperoxidase technique after periodic acid and sodium borohydrate incubation to block endogenous peroxidase activity. Detection of BrdU incorporation to identify endothelial cells in the S-phase of the cell cycle, was performed as previously described; this included acidic hydrolysis for DNA denaturation and microwave (MW) pre-treatment for antigen retrieval (Kass et al. 2000). von Willebrand factor (vWF) was used as an endothelial marker and $\alpha$-smooth muscle actin $(\alpha-S M A)$ immunodetection was performed in order to identify pericytes and vascular smooth muscle

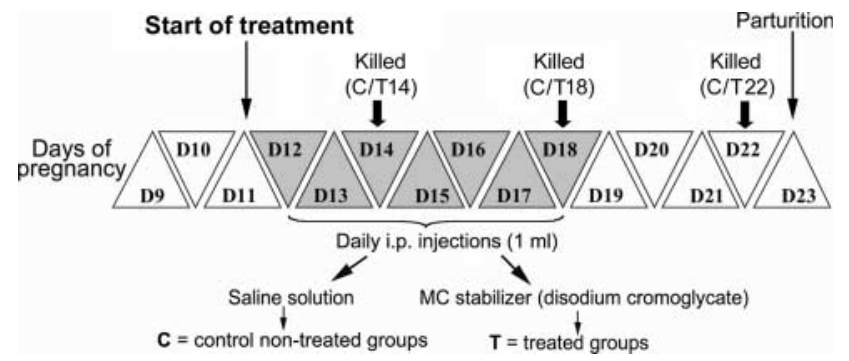

Figure 1 Schematic representation of the experimental protocol. 
cells. After MW pre-treatment, vWF and $\alpha$-SMA immunodetection was done following the previously described protocol (Muñoz de Toro et al. 1998). Primary antibodies were incubated overnight at $4{ }^{\circ} \mathrm{C}$, and dilutions used were: anti-RMCP-I, 1:200 (Moredun Scientific Ltd, Bush Loan, Penicuik, Midlothian, Edinburgh, Scotland); anti$\mathrm{BrdU}, 1: 100$ (clone 85-2C8, Novocastra Laboratories Ltd, Benton Lane, Newcastle upon Tyne, UK); anti-vWF, 1:200 (Dako, Glostrup, Denmark); and anti- $\alpha$-SMA, 1:50 (clone $\alpha$-sm1, Novocastra Laboratories Ltd). The reaction was developed using the streptavidin-biotin peroxidase method and diaminobenzidine (DAB) (Sigma) as a cromogen substrate. Samples were counterstained with Harris or Mayer's haematoxylin (Biopur, Rosario, Argentina) for BrdU and RMCP-I respectively. To detect $\alpha$-SMA and $\checkmark W F$, the colour reactions were intensified with the addition to the cromogen solution of $1 \%$ nickel chloride (Varayoud et al. 2001). These sections were counterstained with nuclear fast red. The slides were dehydrated and mounted with permanent mounting medium (PMyR, Buenos Aires, Argentina).

Each immunohistochemical run included positive and negative controls. For negative controls the primary antibody was replaced with non-immune mouse or rabbit serum (Sigma) or the immunohistochemical run was performed in samples from animals that did not receive BrdU. Suppliers had tested the specificity of the primary antibodies used.

\section{Morphometry}

\section{Quantification of MCs}

Tissue sections were evaluated using an Olympus $\mathrm{BH} 2$ microscope (Olympus Optical Co., Ltd, Tokyo, Japan), with a Dplan $20 \times$ objective (Olympus). The volume fraction, $V_{v}$, of MCs in cervical tissue was determined using the point counting procedure previously described (Luque et al. 1996). Briefly, a square grid inserted in a focusing eyepiece was placed in a systematic random fashion over the entire cervical stroma (Gundersen 1988). The fraction of points occurring within the structure of the MC, $P_{i}$, was determined and then compared with the total number of points lying within the cervical stroma, $P$. The volume fraction was calculated by applying the formula: $V_{\mathrm{v}}=P_{\mathrm{i}} / P$. Toluidine blue and RMCP-I staining procedures were used to obtain the $V_{v}$ of MCs in each rat cervix.

In order to evaluate the effect of MC stabilizing treatment, the percentage of degranulated MCs was compared between MC stabilizer-treated and control rats. MCs with more than three granules outside of the cell shape or with empty cavities in the cytoplasm were considered to be degranulated (Gunin \& Sharov 1998).

\section{Quantification of endothelial proliferation}

A regionalization of the stroma, as described previously (Varayoud et al. 2001, Ramos et al. 2002), was carried out to evaluate $\mathrm{BrdU}$ incorporation by endothelial cells in the uterine cervix. In each section, the subepithelial stroma (an area adjacent to epithelium, $110 \mu \mathrm{m}$ wide from the basement membrane towards the outer layers) and the muscular stroma were evaluated. The percentage of proliferating endothelial cells was calculated by dividing the number of BrdU-positive endothelial cells by the total number of endothelial cells (100 vessels were evaluated in each region studied).

\section{Quantification of vascular areas}

Evaluation of the absolute and relative vascular areas was done on sections immunostained with the anti-vWF antibody and calculated using an image analysis technique. Images of randomly selected fields of cervical stroma (more than 30 fields) were recorded using a Dplan $40 \times$ objective, an Olympus $\mathrm{BH} 2$ microscope and a Sony ExwaveHAM colour video camera. Image analysis was performed using the Image Pro-Plus 4.1.0.1 software (Media Cybernetics, Silver Spring, MD, USA). Using Auto-Pro macro language, an automated standard sequence operation was created to measure the vascular area parameters. In this automated analysis, the images were converted to an 8-bit grey scale and the operator calibrated the grey level so that the background staining of the histological slide was regarded as zero. The area of each vessel was calculated using the immunostaining for vWF combined with a colour segmentation technique, and the sum of all these individual vascular areas was considered as the absolute vascular area. Vessels with cross-sectional areas in the range $50-500 \mu \mathrm{m}^{2}$ were measured. The relative vascular area was determined by dividing the absolute vascular area by the total area occupied by the cervical stroma.

The microscope was correctly set up for Koehler illumination; a reference image of an empty field for the correction of unequal illumination (shading correction) was recorded, and before any measurement started the measurement system was calibrated with a reference slide.

\section{Quantification of vascular maturation}

Using consecutive sections immunostained with a pericyte and smooth muscle cell marker ( $\alpha$-SMA) and with an endothelial cell-specific marker (vWF), the vascular maturation index was determined. This index was calculated by dividing the area occupied by $\alpha$-SMA-positive vessels by the relative vascular area. A total of $100 \mathrm{blood}$ vessels were studied.

\section{Statistics}

Statistical analysis was performed using the one-way ANOVA test. Significance between groups was determined by Newman-Keuls post hoc test, and correlations were performed using Pearson analysis (Siegel 1956). 


\section{Results}

\section{MCs and vascular parameters in the uterine cervix during pregnancy}

An affinity purified antibody developed against RMCP-I was successfully used to identify both non-degranulated and degranulated MCs and established the spatial distribution pattern of connective tissue MCs, the most abundant MC subset described in the uterine cervix. To validate this methodology, regression analysis was performed between the $V_{v}$ values of MCs stained with toluidine blue vs the $V_{v}$ obtained by RMCP-I immunoexpression in adjacent sections. A significant correlation $(r=0.86, P<0.01)$ was obtained (Fig. 2a) between both histotechniques. As mentioned above, the immunohistochemical technique allowed the identification of MCs showing evidence of degranulation. This evidence was the presence of granules released to the pericellular space and of cytoplasmatic halos in MCs (for details see Fig. 2b). Densely packed granules were found in the cytoplasm of immunostained non-degranulated MCs (Fig. 2C).

The relative presence of MCs in the uterine cervix throughout pregnancy was higher during the first half of pregnancy (D9 and D12) with a significant decrease during the second half (D14-D22) (Fig. 3a). The MCs were usually observed in the perivascular zones and predominantly in areas closer to the cervical muscular fibres (see Fig. 3b). Moreover, a higher proportion of MCs showing degranulation was frequently observed during the first half of pregnancy (D9, 98.2 $\pm 1.4 \%$; D12, 99.1 $\pm 0.78 \%$ ) compared with the second half (D14, 91.8 $\pm 1.8 \%$; D22, $90.8 \pm 1.2 \%)$.

Representative photomicrographs of the vascular parameters evaluated are shown in Fig. 4a-c. An increase in endothelial proliferation towards the end of gestation was found both in the subepithelial stroma and in the muscular region (Fig. 4d). The absolute vascular area in the uterine cervix increased significantly during pregnancy with higher values before parturition (Fig. 4e); however, the relative vascular area did not show significant differences (Fig. 4f). These results strongly suggest that blood vessel growth was in parallel with the dramatic size increase that occurs in the uterine cervix towards the end of gestation. The vascular maturation index was high on D12 of pregnancy, and thereafter decreased on D14-D15. From D18 to the time of parturition, there was a high proportion of mature vessels (Fig. 4g).

\section{Inhibition of MC degranulation affects vascular parameters in the uterine cervix}

Animals that received daily injections of $M C$ stabilizer from mid-pregnancy onwards completed a normal gestation. No signs of acute or chronic toxicity were observed in treated mothers, as evaluated by mother weight gain during gestation and by litter sizes recorded when animals were killed (data not shown). All experimental rats (a)
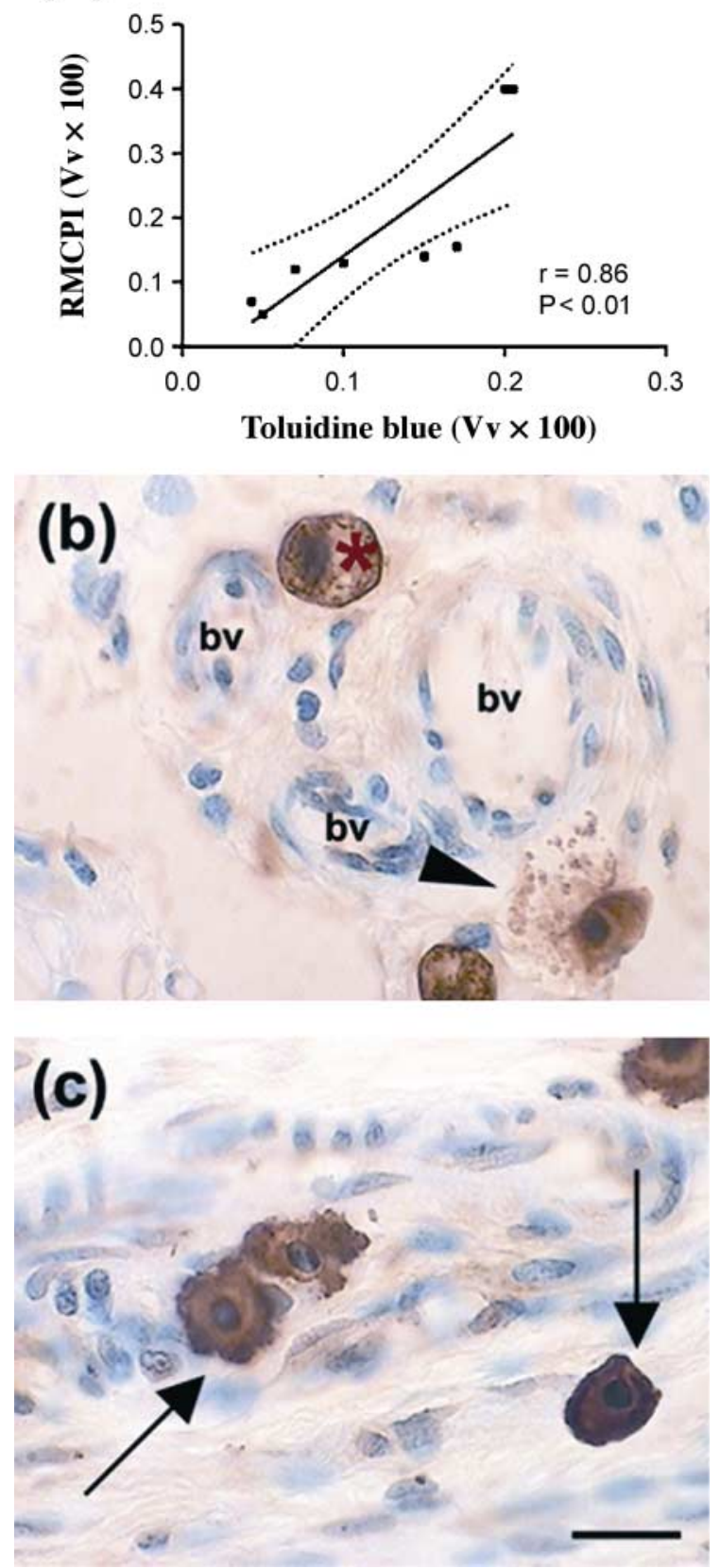

Figure 2 Morphological and histochemical features of MCs. (a) Correlation coefficient, $r$, between the volume fraction $\left(V_{v} \times 100\right)$ of MCs stained with toluidine blue vs those immunostained with anti-RMCPI. (b) and (c) Immunohistochemical detection of MCs using antiRMCP-I antibody to detect RMCP-I, one of the major granule products. This methodology allowed detection of both degranulated and non-degranulated MCs. Representative photomicrographs show different morphological features of MCs: (b) with signs of degranulation, granules outside of the cell shape (arrowhead) and empty cavities in the cytoplasm (asterisk); (c) with densely packed granules that show no signs of degranulation (arrows). bv, blood vessel. Scale bar represents $75 \mu \mathrm{m}$. 


\section{(a)}
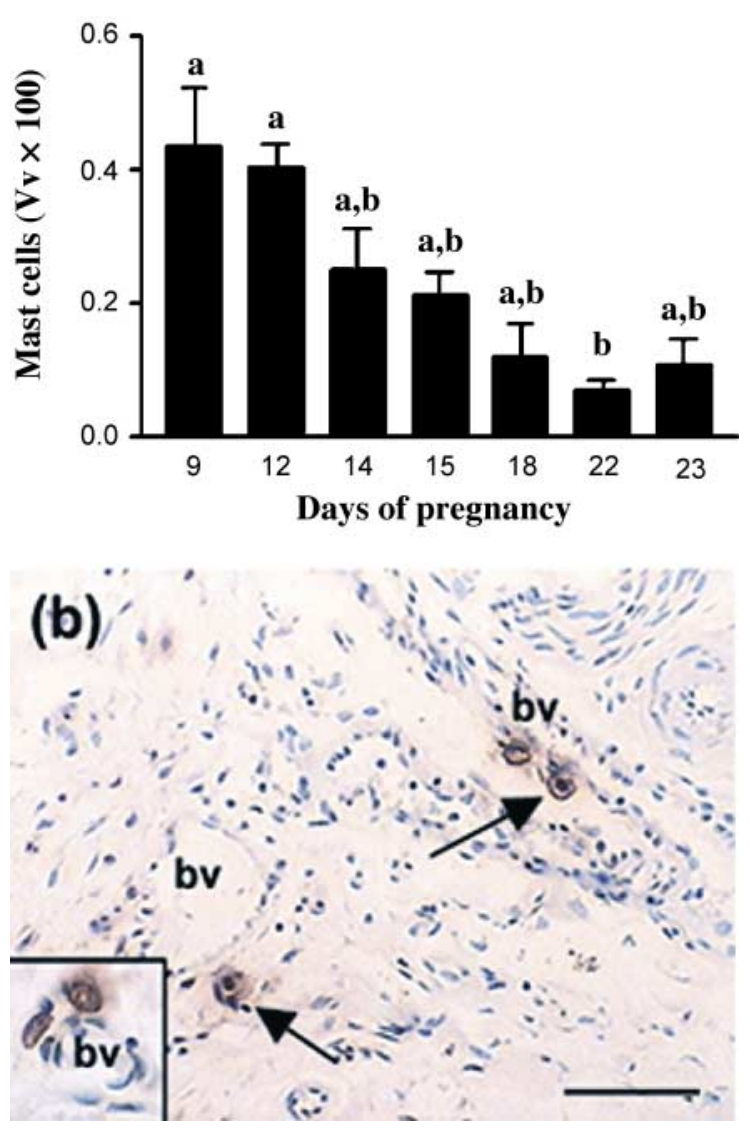

Figure $3 \mathrm{MC}$ distribution in the rat uterine cervix throughout pregnancy. (a) Quantification of volume fraction $\left(V_{v} \times 100\right)$ of MCs showing higher $V_{v}$ on D9 and D12 of pregnancy. Means with different letters are significantly different $(P<0.05)$. (b) Representative fields showing MC (arrows) distribution in the cervix on D12 of pregnancy. The inset shows the characteristic perivascular localization of the MC. bv, blood vessel. Scale bar represents $25 \mu \mathrm{m}$.

showed identical MC distribution to controls, with higher densities around blood vessels in both stromal compartments. Pregnant rats that received MC stabilizer had more than $40 \%$ of non-degranulated MCs (Table 1). In contrast, controls showed signs of degranulation in the majority of MCs. These results showed that the MC stabilizer treatment was partially effective.

On D14, no treatment effects were observed either on endothelial cell proliferation or on relative vascular area (Table 1); on D18 and D22 both vascular parameters showed a significant decrease in the MC stabilizer-treated rats (Fig. 5 and Table 1). Moreover, the vessels of animals treated at D18 and D22 showed a thick layer of $\alpha$-SMApositive cells in both cervix stromal compartments. In fact, the vascular maturation index was significantly higher at D18 and D22 of pregnancy in the group of rats treated with the MC stabilizer (Fig. 5 and Table 1).

\section{Discussion}

The uterine cervix undergoes dramatic adaptation processes during pregnancy, parturition and postpartum (Shi et al. 2000, Montes et al. 2002, Rodríguez et al. 2003). There are striking changes in uterine vascular permeability, growth, density, vasodilatation and blood flow as a physiological response to cellular modifications, especially during pregnancy (Pavelock et al. 2001, Reynolds et al. 2002). In the present study we describe in detail the vascular changes experienced by the rat uterine cervix during pregnancy.

The dramatic increase in cervical volume during pregnancy, due mainly to oedema formation, widespread reorganization of collagen fibres and fibroblastic cell proliferation (Sherwood 1994, Garfield et al. 1998, Leppert 1998, Ramos et al. 2002), could explain the absence of differences in relative vascular area during gestation. However, during the second half of pregnancy, the absolute vascular area of the uterine cervix exhibited a sustained increment, reaching higher values around parturition. This increment in the total area occupied by vessels is associated with a high proliferation rate in the endothelial compartment accompanying the rapid growth of the uterine cervix during pregnancy. These parameters, taken together, strongly suggest an active process of angiogenesis in the rat uterine cervix during pregnancy.

The complex phenomenon of angiogenesis begins with degradation of the basement membrane by cellular proteases, allowing the endothelial cells to penetrate and migrate into the extracellular matrix and then proliferate (Griffioen \& Molema 2000). Recent studies reveal that many factors, including growth factors and integrins, regulate the process of angiogenesis (Levi-Schaffer \& Pe'er 2001). MCs, which have been shown to accumulate around vessels and new capillary sprouting sites, have been implicated in angiogenesis (Hiromatsu \& Toda 2003). In the uterine cervix of the rat, MCs were usually located in the proximity of vessels. A great number of these cells during mid-pregnancy showed evidence of degranulation, as judged by granules released to the pericellular space or by the presence of cytoplasmatic halos. During this period of gestation, significant changes were found in endothelial proliferation and in the total area occupied by blood vessels. The endothelial proliferation rate doubled from D12 to D14 and the absolute vascular area showed a sustained increase starting on D12. In agreement with these results, the significant decrease in the relative proportion of mature blood vessels observed at D14-D15 suggests a relative increment of the population of new vessels, characterized by the absence of pericytes and smooth muscle cells around the endothelial tubes (Darland \& D'Amore 1999). Taking into account all these findings we have proposed the hypothesis that these changes could, at least partially, be mediated by MC degranulation.

Disodium cromoglycate is an MC stabilizing agent reported to have blocking properties on the secretion of 


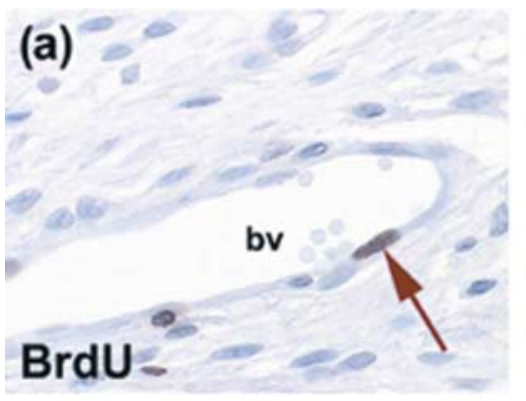

(d)

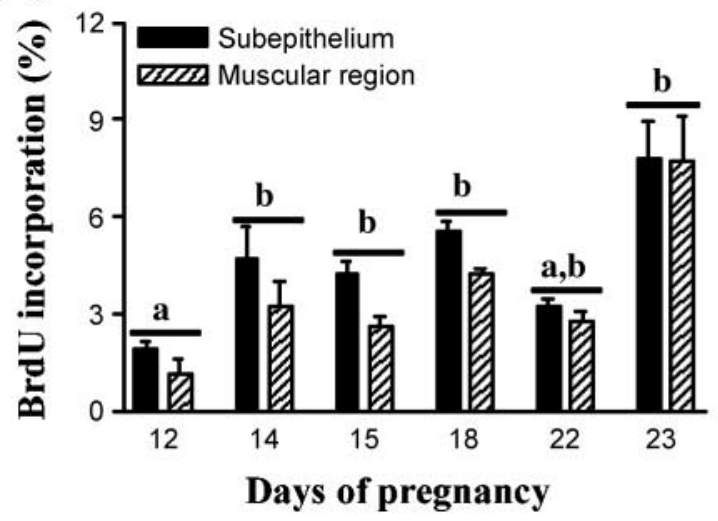

(f)

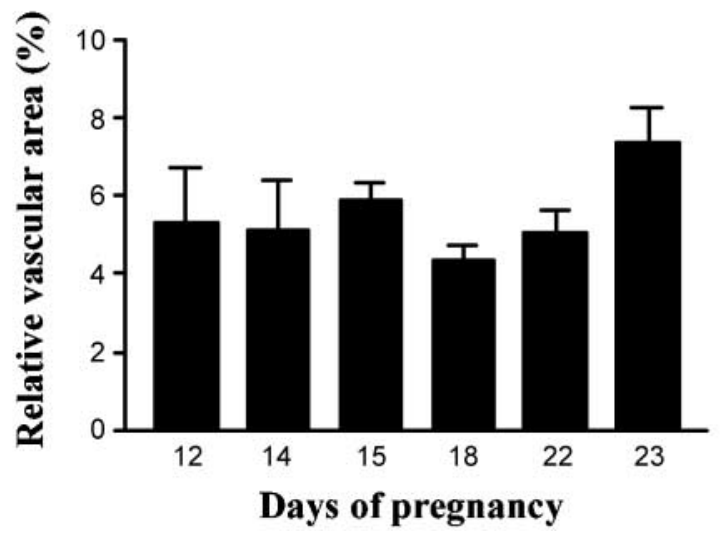

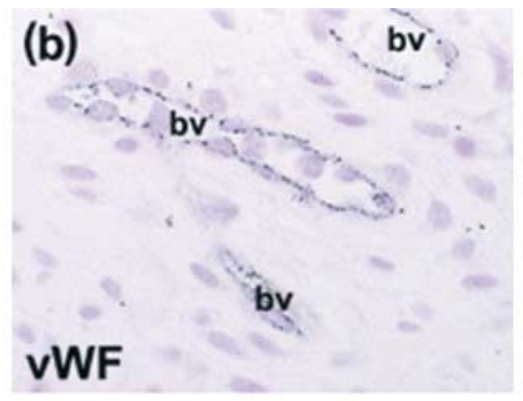

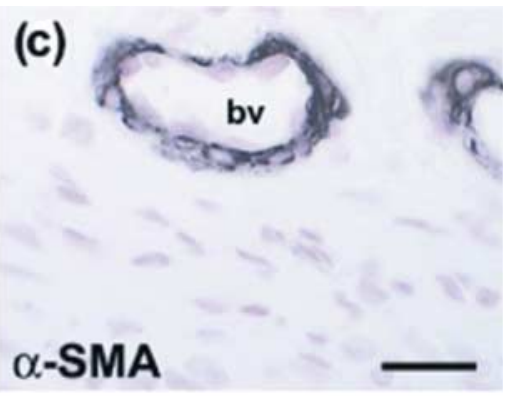

(e)

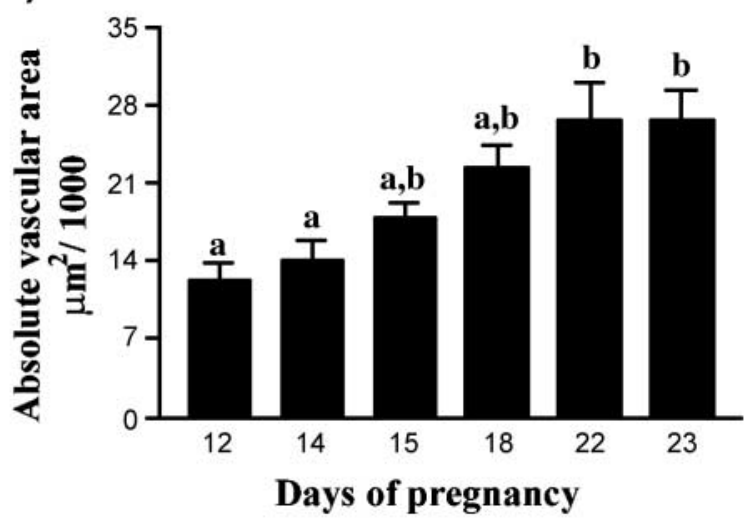

(g)

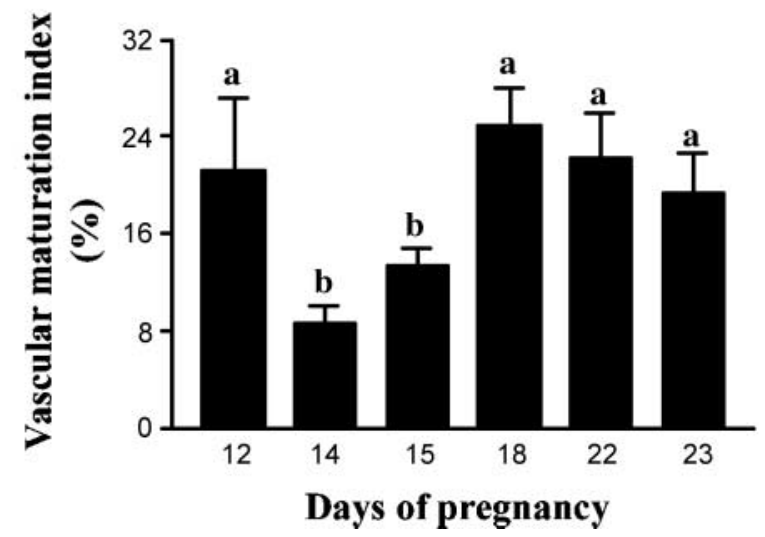

Figure 4 Immunohistochemical detection and quantification of the vascular parameters evaluated during pregnancy. (a) Photomicrograph showing a subepithelial blood vessel of a rat cervix with a BrdU-positive endothelial cell (arrow). (b) Immunohistochemical localization of the endothelial cell specific marker, von Willebrand factor (vWF). (c) Using an anti- $\alpha$-smooth muscle actin ( $\alpha$-SMA) antibody, the presence of pericytes and vascular smooth muscle cells was determined in order to study the vascular maturation index. bv, blood vessel. Scale bar represents $25 \mu \mathrm{m}$. (d) Percentages of BrdU incorporation of endothelial cells in the stromal compartments (subepithelium and muscular region) of the uterine cervix during pregnancy. (e) Absolute and (f) relative vascular areas expressed as $\mu \mathrm{m}^{2} \times 1000$ and the percentage of total area respectively. Note that the absolute vascular area showed a significant increase during gestation. (g) Quantification of vascular maturation index as defined in Materials and Methods. Bars represent means \pm S.E.M. from at least five to six animals per day of pregnancy. Means with different letters are significantly different $(P<0.05)$.

granules (Tainsh et al. 1991). There were no significant differences in the volume density of MCs between treated and control groups; however, large rounded MCs with densely packed granules were observed in treated rats during D14-D18 of pregnancy and the proportion of degranulated MCs was significantly reduced in animals treated with disodium cromoglycate. Dramatic changes in vascular parameters were observed in the uterine cervix of treated rats. Endothelial proliferation and relative vascular area showed significant decreases compared with controls and a large proportion of mature blood vessels could be observed in treated rats, strongly suggesting a diminished process of new vessel formation. Moreover, the effects of the MC stabilizer on these vascular 
Table 1 Quantification of MCs, endothelial proliferation and relative vascular area in the uterine cervix of controls (C) compared with mast cell stabilizer-treated (T) rats on D14, D18 and D22 of pregnancy ${ }^{\mathrm{a}}$.

\begin{tabular}{|c|c|c|c|c|c|c|}
\hline \multirow[b]{2}{*}{ Parameters } & \multicolumn{2}{|c|}{ D14 } & \multicolumn{2}{|c|}{ D18 } & \multicolumn{2}{|c|}{ D22 } \\
\hline & $\mathrm{C}$ & $\mathrm{T}$ & $\mathrm{C}$ & $\mathrm{T}$ & $\mathrm{C}$ & $\mathrm{T}$ \\
\hline $\operatorname{MCs}\left(V_{v} \times 100\right)$ & $0.12 \pm 0.02$ & $0.08 \pm 0.02$ & $0.12 \pm 0.01$ & $0.09 \pm 0.02$ & $0.08 \pm 0.02$ & $0.08 \pm 0.01$ \\
\hline Percentage of non-degranulated MCs & $8.20 \pm 0.52$ & $45.6 \pm 2.51^{*}$ & $6.45 \pm 0.99$ & $43.42 \pm 1.85^{*}$ & $9.12 \pm 0.76$ & $8.34 \pm 1.56$ \\
\hline Endothelial BrdU incorporation (\%) & $7.97 \pm 1.66$ & $6.44 \pm 0.71$ & $10.2 \pm 0.3$ & $6.81 \pm 0.66^{*}$ & $6.41 \pm 0.44$ & $4.14 \pm 0.41^{*}$ \\
\hline Relative vascular area $(\%)^{\mathrm{b}}$ & $5.10 \pm 1.31$ & $3.42 \pm 0.84$ & $3.12 \pm 0.41$ & $1.46 \pm 0.39 *$ & $4.80 \pm 0.67$ & $3.29 \pm 0.10^{*}$ \\
\hline Vascular maturation index ${ }^{\mathrm{C}}$ & $0.09 \pm 0.01$ & $0.29 \pm 0.05^{*}$ & $0.30 \pm 0.06$ & $0.69 \pm 0.12 *$ & $0.22 \pm 0.04$ & $0.43 \pm 0.06^{*}$ \\
\hline
\end{tabular}

${ }^{\text {a }}$ Results are expressed as the mean \pm S.E.M. ( $n=5-6$ animals).

b Obtained by dividing the absolute vascular area by the total area occupied by the uterine cervical stroma.

${ }^{\mathrm{c}}$ Obtained by dividing the positive $\alpha$-actina vascular area by the relative vascular area.

For each day of pregnancy, asterisks indicate that values of treated groups are significantly different $(P<0.05)$ from controls.
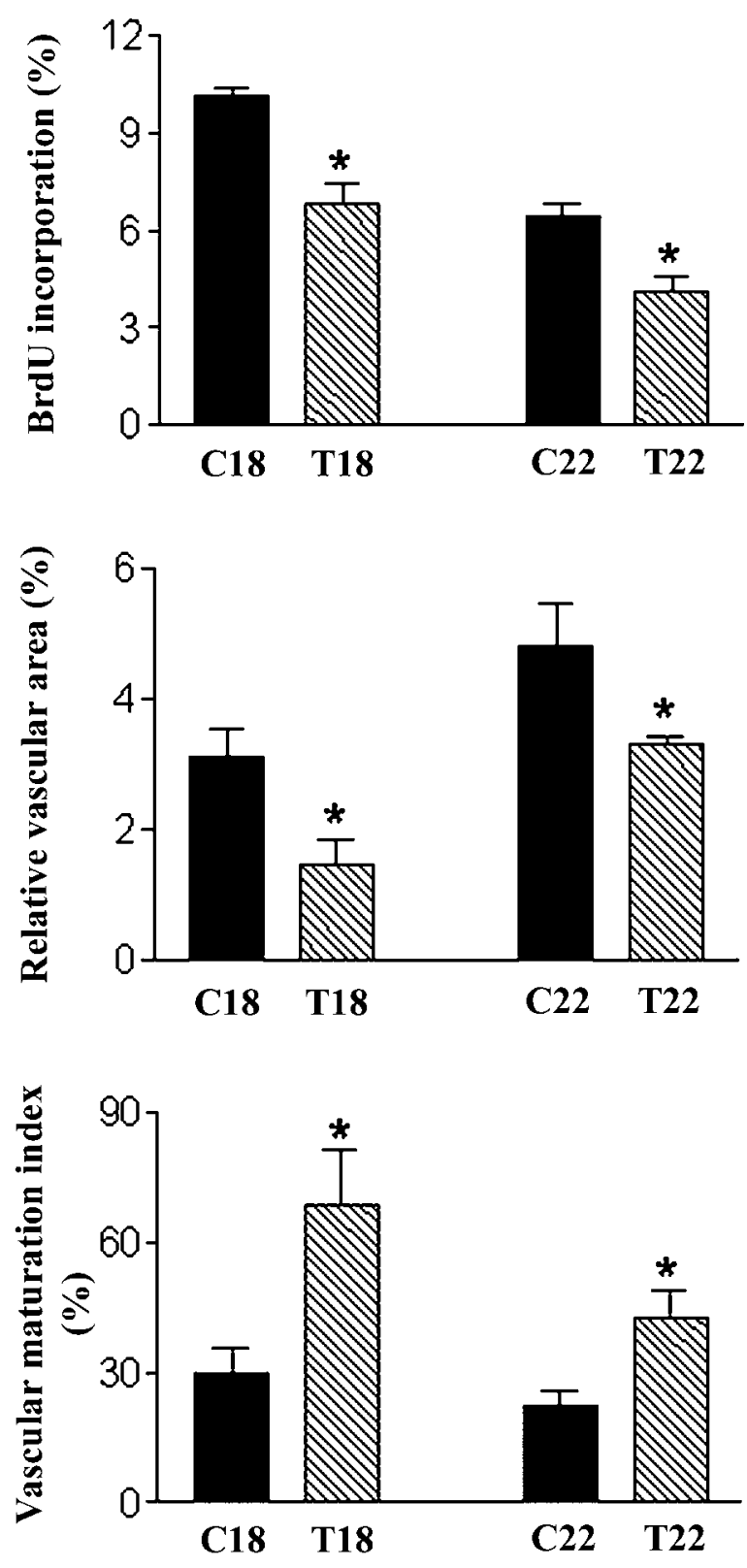

www.reproduction-online.org parameters were sustained beyond the end of the treatment, since animals killed on D22 of pregnancy showed reduced endothelial proliferation and a large proportion of mature vessels.

The extracellular matrix of the uterine cervix is composed mainly of collagen (types I and III), elastic fibres and proteoglycans (Minamoto et al. 1987, Luque et al. 1998). During pregnancy the collagen network maintains the cervix as a rigid and closed structure in order to support the foetus in the uterus and prevent infections arising from the vagina. However, during angiogenesis, local and controlled degradation of connective tissue is essential for neovascular sprouting and elongation (Kahari \& SaarialhoKere 1997). Mast cells could mediate this process since it has been demonstrated that activated MCs have the potential to stimulate the production of matrix metalloproteinases (MMPs) by endometrial stromal cells and to set up a cascade of MMP activation within the endometrium (Zhang et al. 1998). It has been demonstrated that histamine and heparin have potent angiogenic effects. A number of cytokines release histamine from MCs; this acts as an angiogenic factor interacting with both $\mathrm{H}_{1}$ and $\mathrm{H}_{2}$ receptors (Sorbo et al. 1994). Very low levels of IL-1 were required to stimulate histamine release from $M C$ granules (Subramanian \& Bray 1987), these low levels of interleukins are present in the cervix during gestation (Maul et al. 2002). During parturition higher levels of IL-1 were detected, however in this work we demonstrated that very few MCs could be observed in late gestation. These events, taken together, allow us to speculate about the existence of a timing control of IL-1-mediated histamine release during specific periods of gestation. MCs from rat

Figure 5 Determination of vascular parameters in control (C) and MC stabilizer-treated (T) rats, killed on D18 and D22 of pregnancy. In both days of pregnancy, the treatment with MC stabilizer significantly affected the normal development of the angiogenesis process. Bars represent mean values ( \pm S.E.M.) from control groups (black bars) and MC stabilizer-treated groups (hatched bars) (five to six animals per group). *Statistically significant differences between controls and treated rats on the same day of pregnancy $(P<0.05)$. 
tissues were shown to possess bFGF in their cytoplasmic granules that can be released through degranulation $(\mathrm{Qu}$ et al. 1998). Heparin stimulates endothelial cell chemotaxis and proliferation and, by binding bFGF, maintains its biologically active form and is protected from proteolysis (Levi-Schaffer \& Pe'er 2001). These events could permit local activation of MMPs resulting in foci of tissue breakdown that provide space for endothelial sprouting and proliferation (Tozzi et al. 1998, Grützkau et al. 1998). Since the pharmacology and mechanisms of action of MC stabilizing agents are not fully understood, a direct action of disodium cromoglycate on endothelial proliferation and related vascular parameters cannot be ruled out.

In the present study we investigated quantitative MC distribution and temporal associations with changes in vascular growth and endothelial proliferation in the cervix of intact pregnant rats. Although MC activation has been related to biomechanical and contractile properties of the cervix (Spanggaard et al. 1997, Bytautiene et al. 2002), to our knowledge this is the first report that brings evidence that $\mathrm{MC}$ degranulation could be a necessary process which contributes to the normal angiogenesis of the rat cervix during pregnancy.

Previous studies have suggested that nitric oxide (NO) is an important local mediator in the uterus and cervix during pregnancy and parturition (Garfield et al. 1998). $\mathrm{NO}$ production in the cervix is low during gestation and becomes upregulated once pregnancy advances to term (Maul et al. 2003). Moreover, NO prevents MC degranulation, mediator release and cytokine expression (Forsythe et al. 2001, Coleman 2002, Steiner et al. 2003). Taking into account these results, we propose that the absence of $\mathrm{NO}$ in the cervix during pregnancy could be necessary for the MC to exert its stimulatory effects on angiogenesis.

Further investigations are necessary to elucidate the possible implications of abnormal vascular development on the physiological process of cervical ripening and parturition.

\section{Funding}

This study was supported by grants from the Argentine National Council for Science and Technology (CONICET) (PIP 528/98), the Argentine National Agency for the Promotion of Science and Technology $\left(\mathrm{ANPC}_{\mathrm{y}} \mathrm{T}\right)$ (PICT-99 $\mathrm{N}^{\circ}$ 5-7001) and Universidad Nacional del Litoral (CAI + D 027-195). J V and V L B are Fellows, and J G R and E H L are Career Investigators of the CONICET.

\section{References}

Benítez-Bribiesca L, Wong A, Utrera D \& Castellanos E 2001 The role of mast cell tryptase in neoangiogenesis of premalignant and malignant lesions of the uterine cervix. Journal of Histochemistry and Cytochemistry 49 1061-1062.

Burd PR, Rogers HW, Gordon JR, Martin CA, Jayaraman S, Wilson SD, Dvorak AM, Galli SJ \& Dorf ME 1989 Interleukin 3-dependent and -independent mast cell stimulated with $\lg \mathrm{E}$ and antigen express multiple cytokines. Journal of Experimental Medicine $\mathbf{1 7 0}$ $245-257$

Bytautiene E, Vedernikov YP, Saade GR, Romero R \& Garfield RE 2002 Endogenous mast cell degranulation modulates cervical contractility in the guinea pig. American Journal of Obstetrics and Gynecology 186 438-445.

Coleman JW 2002 Nitric oxide: a regulator of mast cell activation and mast cell-mediated inflammation. Clinical and Experimental Immunology 129 4-10.

Darland DC \& D'Amore PA 1999 Blood vessel maturation: vascular development comes of age. Journal of Clinical Investigation 103 $157-158$.

Folkman J 1982 Angiogenesis: initiation and control. Annals of the New York Academy of Sciences 401 212-227.

Forsythe P, Gilchrist M, Kulka M \& Befus AD 2001 Mast cells and nitric oxide: control of production, mechanisms of response. International Immunopharmacology 1 1525-1541.

Freeman M 1994 The neuroendocrine control of the ovarian cycle of the rat. In The Physiology of Reproduction, pp 613-658. Eds E Knobil \& JD Neill. New York: Raven Press.

Fukushima N, Satoh T, Sano M \& Tokunaga O 2001 Angiogenesis and mast cells in non-Hodgkin's lymphoma: a strong correlation in angioimmunoblastic T-cell lymphoma. Leukemia and Lymphoma 42 709-720.

Garfield RE, Saade G, Buhimschi C, Buhimschi I, Shi L, Shi SQ \& Chwalisz K 1998 Control and assessment of the uterus and cervix during pregnancy and labour. Human Reproduction Update $\mathbf{4}$ 673-695.

Gibson S \& Miller HRP 1986 Mast cell subsets in the rat distinguished immunohistochemically by their content of serine proteinases. Immunology 58 101-104.

Griffioen AW \& Molema G 2000 Angiogenesis: potentials for pharmacologic intervention in the treatment of cancer, cardiovascular diseases, and chronic inflammation. Pharmacological Review 52 237-268.

Grützkau A, Krüger-Krasagakes S, Baumeister H, Schwarz C, Kögel H, Welker P, Lippert U, Henz BM \& Möller A 1998 Synthesis, storage and release of vascular endothelial growth factor/vascular permeability factor (VEGF/VPF) by human mast cells: implications for the biological significance of $\mathrm{VEGF}_{206}$. Molecular Biology of the Cell 9 875-884.

Gundersen HJG, Bendtsen TF, Korbo L, Marcussen N, Moller A, Nielsen K, Nyengaard JR, Pakkenberg B, Sorensen FB, Vesterby A \& West MJ 1988 Some new, simple and efficient stereological methods and their use in pathological research and diagnosis. Acta Pathologica, Microbiologica et Immunologica Scandinavica 96 379-394.

Gunin AG \& Sharov AA 1998 Role of mast cells in oestradiol effects on the uterus of ovariectomized rats. Journal of Reproduction and Fertility 112 61-68.

Hiromatsu Y \& Toda S 2003 Mast cells and angiogenesis. Microscopy Research and Technique 60 64-69.

Hyder SM \& Stancel GM 2000 Regulation of VEGF in the reproductive tract by sex-steroid hormones. Histology and Histopathology $15325-334$.

Junqueira LCU, Zugaib M, Montes GS, Toledo OMS, Krisztán RM \& Shigihara KM 1980 Morphologic and histochemical evidence for the occurrence of collagenolysis and for the role of neutrophilic polymorphonuclear leukocytes during cervical dilation. American Journal of Obstetrics and Gynecology 138 273-281.

Kahari VM \& Saarialho-Kere U 1997 Matrix metalloproteinases in skin. Experimental Dermatology 6 199-213.

Kass L, Varayoud J, Ortega H, Muñoz-de-Toro M \& Luque EH 2000 Detection of bromodeoxyuridine in formalin-fixed tissue. DNA denaturation following microwave or enzymatic digestion pretreatment is required. European Journal of Histochemistry $\mathbf{4 4}$ 185-191.

Leppert PC 1998 The biochemistry and physiology of the uterine cervix during gestation and parturition. Prenatal and Neonatal Medicine 3 103-105. 
Levi-Schaffer F \& Pe'er J 2001 Mast cells and angiogenesis. Clinical and Experimental Allergy 31 521-524.

Luque EH, Ramos JG, Rodriguez HA \& Muñoz-de-Toro MM 1996 Dissociation in the control of cervical eosinophilic infiltration and collagenolysis at the end of pregnancy or after pseudopregnancy in ovariectomized steroid-treated rats. Biology of Reproduction $\mathbf{5 5}$ $1206-1212$.

Luque EH, Muñoz-de-Toro MM, Ramos JG, Rodriguez HA \& Sherwood OD 1998 Role of relaxin and estrogen in the control of eosinophilic invasion and collagen remodelling in rat cervical tissue at term. Biology of Reproduction 59 795-800.

Maul H, Nagel S, Welsch G, Schafer A, Winkler M \& Rath W 2002 Messenger ribonucleic acid levels of interleukin-1 beta, interleukin- 6 and interleukin- 8 in the lower uterine segment increased significantly at final cervical dilatation during term parturition, while those of tumor necrosis factor alpha remained unchanged. European Journal of Obstetrics, Gynecology and Reproductive Biology 102 143-147.

Maul H, Longo M, Saade GR \& Garfield RE 2003 Nitric oxide and its role during pregnancy: from ovulation to delivery. Current Pharmaceutical Design 9 359-380.

Maymon E, Romero R, Pacora P, Gomez R, Athayde N, Edwin S \& Yoon BH 2000 Human neutrophil collagenase (matrix metalloproteinase 8) in parturition, premature rupture of the membranes, and intrauterine infection. American Journal of Obstetrics and Gynecology 183 94-99.

Minamoto T, Arai K, Hirakawa S \& Nagai Y 1987 Immunohistochemical studies on collagen types in the uterine cervix in pregnant and nonpregnant states. American Journal of Obstetrics and Gynecology 156 138-144.

Montes GS \& Luque EH 1988 Effects of ovarian steroids on vaginal smears in the rat. Acta Anatomica 133 192-199.

Montes GS, Zugaib M, Joazeiro PP, Varayoud J, Ramos JG, Muñozde-Toro M \& Luque EH 2002 Phenotypic modulation of fibroblastic cells in the mucous layer of the human uterine cervix at term. Reproduction 124 783-790.

Mori A, Zhai Y, Toki T, Nikaido T \& Fujii S 1997 Distribution and heterogeneity of mast cells in the human uterus. Human Reproduction 12 368-372.

Muñoz-de-Toro MM, Maffini MV, Giardina RH \& Luque EH 1998 Processing fine needle aspirates of prostate carcinomas for standard immunocytochemical studies and in situ apoptosis detection. Pathology Research and Practice 194 631-636.

Norrby K 2002 Mast cells and angiogenesis. Acta Pathologica, Microbiologica et Immunologica Scandinavica AMPIS $\mathbf{1 1 0}$ 355-371.

Pavelock K, Braas KM, Ouafik L, Osol G \& May V 2001 Differential expression and regulation of the vascular endothelial growth factor receptors neuropilin-1 and neuropilin-2 in rat uterus. Endocrinology 142 613-622.

Qu Z, Kayton RJ, Ahmadi P, Liebler JM, Powers MR, Planck SR \& Rosenbaum JT 1998 Ultrastructural immunolocalization of basic fibroblast growth factor in mast cell secretory granules: morphological evidence for bFGF release through degranulation. Journal of Histochemistry and Cytochemistry 46 1119-1128.

Ramos JG, Varayoud J, Bosquiazzo VL, Luque EH \& Muñoz-de-Toro M 2002 Cellular turnover in the rat uterine cervix and its relationship to estrogen and progesterone receptors dynamics. Biology of Reproduction 67 735-742.

Reynolds LP, Grazul-Bilska AT \& Redmer DA 2002 Angiogenesis in the female reproductive organs: pathological implications. International Journal of Experimental Pathology 83 151-163.

Rodríguez HA, Kass L, Varayoud J, Ramos JG, Ortega H, Durando M, Muñoz-de-Toro M \& Luque EH 2003 Collagen remodelling in the guinea-pig uterine cervix at term is associated with a decrease in PR expression. Molecular Human Reproduction 9 807-813.
Rudolph MI, Reinicke K, Cruz MA, Gallardo V, Gonzalez C \& Bardisa L 1993 Distribution of mast cells and the effect of their mediators on contractility in human myometrium. British Journal of Obstetrics and Gynecology 100 1125-1130.

Selvan RS, Butterfield JH \& Krangel MS 1994 Expression of multiple chemokine genes by a human mast cell leukemia. Journal of Biological Chemistry $26913893-13898$.

Sherwood OD 1994 Relaxin. In The Physiology of Reproduction, pp 861-1009. Eds E Knobil \& JD Neill. New York: Raven Press.

Shi L, Shi SQ, Saade GR, Chwalisz K \& Garfield RE 2000 Studies of cervical ripening in pregnant rats: effects of various treatments. Molecular Human Reproduction 6 382-389.

Siegel S 1956 Nonparametric statistics for the behavioral sciences. New York: McGraw-Hill.

Sorbo J, Jakobsson A \& Norrby K 1994 Mast-cell histamine is angiogenic through receptors for histamine 1 and histamine 2. International Journal of Experimental Pathology 75 43-50.

Spanggaard H, Knudsen U, Uldbjerg N, Jeziorska M, Woolley D \& Danielsen C 1997 Mast cells in cervical ripening - an immunohistochemical and biomechanical study in rats. European Journal of Obstetrics and Gynecology and Reproductive Biology 73 91-97.

Steiner DRS, Gonzalez NC \& Wood JG 2003 Mast cells mediate the microvascular inflammatory response to systemic hypoxia. Journal of Applied Physiology 94 325-334.

Stygar D, Wang H, Stjernholm Vladic Y, Ekman G, Eriksson H \& Sahlin L 2002 Increased level of matrix metalloproteinases 2 and 9 in the ripening process of the human cervix. Biology of Reproduction 67 889-894.

Subramanian N \& Bray MA 1987 Interleukin 1 release histamine from human basophils and mast cells in vitro. Journal of Immunology $138271-275$.

Tainsh KR, Lau HY, Liu WL \& Pearse FL 1991 The human skin mast cells: a comparison with the human lung cell and a novel mast cell type, the uterine mast cell. Agents and Actions 33 $16-19$.

Thomson AJ, Telfer JF, Young A, Campbell S, Stewart CJR, Cameron IT, Greer IA \& Norman JE 1999 Leukocytes infiltrate the myometrium during human parturition: further evidence that labour is an inflammatory process. Human Reproduction $\mathbf{1 4}$ 229-236.

Tozzi CA, Thakker-Varia S, Yu SY, Bannett RF, Peng BW, Poiani GJ, Wilson FJ \& Riley DJ 1998 Mast cell collagenase correlates with the regression of pulmonary vascular remodeling in the rat. American Journal of Respiratory Cellular and Molecular Biology 18 497-510.

Varayoud J, Ramos JG, Joazeiro PP, Montes GS, Muñoz-de-Toro M \& Luque EH 2001 Characterization of fibroblastic cell plasticity in the lamina propria of the rat uterine cervix at term. Biology of Reproduction 65 375-383.

Vincent AJ, Zhang J, Ostor A, Rogers PAW, Affandi B, Kovacs G \& Salamonsen LA 2000 Matrix metalloproteinase-1 and -3 and mast cells are present in the endometrium of women using progestin-only contraceptives. Human Reproduction $\mathbf{1 5}$ $123-130$.

Wolman M 1971 Amyloid, its nature and molecular structure. Comparison of a new toluidine blue polarized light method with traditional procedures. Laboratory Investigation 25 104-110.

Zhang J, Nie G-Y, Wang J, Woolley DE \& Salamonsen LA 1998 Mast cell regulation of human endometrial matrix metalloproteinases: a mechanism underlying menstruation. Biology of Reproduction 59 $693-703$.

Received 24 September 2003

First decision 29 October 2003

Accepted 8 December 2003 